\title{
Relaciones mediadas por tecnologías digitales. Reseña del libro Kentukis (2018, Random House) de Samanta Schweblin.
}

Guillermina Yansen ${ }^{1}$

Cómo citar: Yansen, G. (2019). Relaciones mediadas por tecnologías digitales. Reseña del libro Kentukis (2018, Random House) de Samanta Schweblin. Revista Hipertextos 12(7), pp. 139-155. DOI: https://doi.org/10.24215/23143924e007

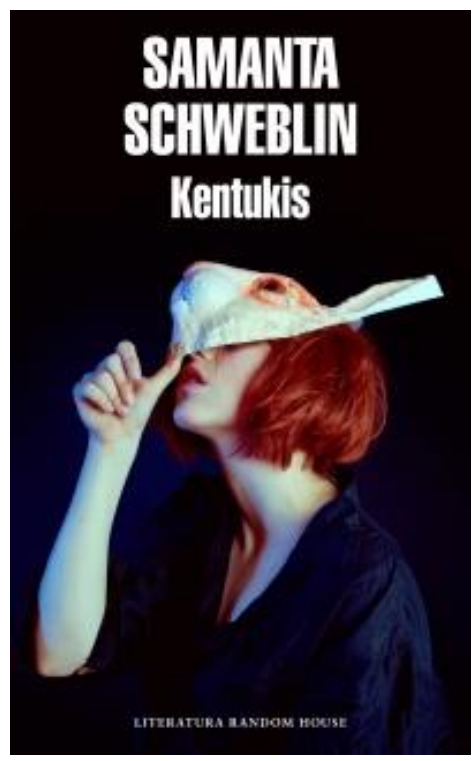

Ficha Técnica

Título: Kentukis

Año de 1a edición: 2018

Autora: Samanta Schweblin

Editorial: Random House

Págs: 221

Género literario: novela

\footnotetext{
${ }^{1}$ Becaria posdoctoral CONICET (UM-UBA). Dra. en Ciencias Sociales (UBA). Mg. en Ciencia Política y Sociología (FLACSO Argentina). Licenciada en Sociología (Facultad de Ciencias Sociales, UBA). Integra el equipo e-TCS (Equipo de Estudios de Tecnología, Capitalismo y Sociedad) del Centro CTS. Contacto: guillerminayansen@e-tcs.org (o gmail).
} 
En este breve escrito nos proponemos reseñar Kentukis (2018, Ed. Random House), novela de ficción y libro más reciente de la autora argentina Samanta Schweblin.

El ejercicio que ensayamos, algo atípico en revistas académicas que no se dediquen específicamente a tópicos culturales, consiste más precisamente en reseñar esta novela atendiendo a la visión sobre la tecnología que allí se plasma y utilizando la ficción como insumo para reconstruirla o, mejor dicho, interpretarla. Naturalmente, la resultante no será el reflejo de la visión que prima en la sociedad. Tampoco espejará la que abunda en el género novela, ni mucho menos en la ficción en general. Será, en cambio, un mojón en el conocimiento sobre los imaginarios que circulan en nuestra cultura ficcional de la tecnología, particularmente de la tecnología digital. ¿Cómo observamos a las tecnologías digitales desde la ficción? ¿Qué nos (pre)ocupa en torno a ellas? ¿Cómo es el mundo que las rodea? ¿Qué aspectos de la relación tecnología-sociedad tienen protagonismo? ¿Cuáles, en cambio, permanecen opacos? Estas preguntas intentarán ser contestadas, entonces, en torno a un imaginario ficcional posible, siempre en relación a esta novela y sin pretensión de generalización.

La relevancia de Kentukis viene dada por, al menos, dos aspectos. En primer lugar, por su temática. Como veremos en detalle a continuación, los protagonistas de la novela, los kentukis, son tecnologías digitales (TD) que median relaciones humanas. De este modo, la tecnología digital constituye el centro de la trama y no una figura meramente lateral.

El segundo aspecto que le otorga relevancia a la novela es la notoriedad que ha cobrado su autora en los últimos años. Nacida en Buenos Aires en 1978 e instalada desde hace algunos años en Berlín, Samanta Schweblin ha publicado ya una buena cantidad de obras literarias y obtenido una importante cantidad de premios que le han valido el reconocimiento nacional e internacional. Entre sus obras más destacadas se cuenta "Siete casas vacías" (Páginas de espuma, 2015), una colección de cuentos por la que obtuvo el premio español de Narrativa Breve Rivera del Duero 2015. Asimismo, su primera obra en el género novela, "Distancia de Rescate" (2014, Random House), además de haber ganado dos importantes premios en $2018^{2}$, fue elegida en 2017 como finalista del premio Man

${ }^{2}$ Por dicha obra ganó el premio Tournament of Books y fue la primera autora argentina en obtener el premio Shirley Jackson. 
Booker International Prize, -según entendidos- uno de los premios más prestigiosos de la actualidad. Traducida a más de 23 idiomas, esa misma novela, cabe destacar, le abrió las puertas al cine de la mano de nada menos que Netflix, en cuyo proyecto se encuentra trabajando actualmente la autora. En fin, con este panorama, es de esperar que Kentukis tenga una importante llegada al gran público. Al momento, se encuentra entre los libros más vendidos en librerías reconocidas en Argentina (Cúspide, Eterna Cadencia, entre otras).

El presente escrito se divide en tres partes. En la primera aportamos un resumen de la novela. Luego, [alerta spoiler $]^{3}$ dedicamos dos secciones a reseñar la trama con algo más de detalle con el foco puesto en las TD. En la sección 2 aportamos lo que entendemos es la visión general, el lente con el que son observadas las tecnologías digitales en esta novela. En la sección 3 rastreamos algunos hilos temáticos más específicos sobre las TD. Sospechará el lector, a esta altura, que no pretendemos ofrecer una reseña literaria, ni aparentar expertise alguna en dicha materia.

\section{Un resumen de Kentukis}

La novela narra diversas historias de los más variados personajes vinculándose a kentukis en distintas ciudades y pueblos a lo largo del globo. Es a través de estas historias, sin más conexión entre sí que la presencia de esta especie de mascota tecnológica, que el texto nos propone descubrir lentamente qué son los kentukis y cómo son las relaciones que se establecen con ellos.

Un kentuki es un artefacto tecnológico vestido de peluche que conecta a dos personas: a quien adquiere el kentuki (el "amo") y a quien lo controla de manera remota (el "ser"). Así, en realidad, el kentuki necesita de dos dispositivos para funcionar.

De un lado, nos encontramos con el "muñeco" o "mascota" - el kentuki propiamente dicho-, cuyo comprador (o "amo") tendrá como compañero. Sus funcionalidades digitales y mecánicas son limitadas. En cuanto a las primeras, el "bichito" puede ver a través de una pantalla, puede escuchar y emitir sonidos,

\footnotetext{
3 Aunque evitaremos referencias a información específica sobre el desenlace de las historias, brindaremos algunos datos que no necesariamente remiten a la mera presentación de las mismas. Queda entonces advertido el lector. Se comprenderá, también, que, por esta misma razón, algunas afirmaciones podrán resultar poco fundadas. El lector que se acerque a la novela juzgará, luego de su lectura, si tienen o no algún tipo de asidero.
} 
pero no puede hablar, filmar, grabar sonidos ni tomar fotografías (algo que en algún momento de la novela se explicará por "las políticas de privacidad"). Todo ello limitado más aún por sus funcionalidades mecánicas. Su soporte es un peluche con forma de animalito, de colores estridentes, una altura de no más de $30 \mathrm{~cm}$ y unas pequeñas ruedas debajo de sí. Impulsadas por un motor a batería, estas le permiten trasladarse a velocidad muy modesta en una superficie plana, pero no subir o bajar escalones. Los hay dragones, cuervos, osos pandas, topos, conejos y lechuzas. De este modo, el potencial de sus funciones digitales depende en gran medida de su soporte, que lo hace a su vez depender de los caprichos de su amo. Si un amo deja a un kentuki patas para arriba, mirando una pared, la visión del kentuki quedará naturalmente restringida a un rectángulo gris de cal. Particularmente, es crucial que el kentuki nunca se descargue completamente. El cargador (similar a la base de una pava eléctrica) está en poder del amo, pero el kentuki puede ir hacia la base de carga por sus propios medios, en la medida en que le sea posible. Como veremos, parte del asunto está en descubrir todas las potencias que tiene una tecnología, a priori, tan limitada.

El otro dispositivo necesario para el funcionamiento de estas mascotas es una computadora o tablet en la que instalar el controlador del kentuki, una app, también paga, que permitirá establecer una conexión y manejar al kentuki, sea donde fuere que el mismo se encuentre físicamente. Manejar, como se deduce un poco de lo dicho más arriba, implica "despertarlo" (conectarse a la app) para que pueda ver, oír, moverse y, eventualmente, establecer algún tipo de comunicación con su "amo".

En síntesis, la novela narra historias de relaciones mediadas por kentukis: un "amo" o "ama", que es quien recibe al kentuki en su hogar, y un "ser", que es quien auspicia de alma del kentuki vía su controlador, y que únicamente mira una pantalla en su computadora, mientras el muñeco se pasea por algún sitio que el amo haya dispuesto. En esta novela se puede, entonces, "tener" un kentuki o "ser" un kentuki.

Las relaciones mediadas por kentukis presentan dos particularidades. En primer lugar, no hay forma de preseleccionar a los seres humanos que establecerán la conexión. Algún tipo de algoritmo desconocido, establecerá, al momento de encender el bichito por primera vez, una conexión azarosa entre una persona y otra, que bien puede estar en otra parte del mundo o en el piso 
inmediatamente debajo de su departamento, puede ser un niño, un anciano o una adolescente, y puede tener las más variadas motivaciones y formas de ser, como en la vida misma. En este comienzo, ninguno de lxs conectadxs puede saber nada sobre las respectivas identidades ni ubicaciones, estableciéndose una relación completamente anónima. La segunda particularidad es que dicha conexión será la única que podrá transitar ese kentuki durante su vida útil. Si la conexión no gusta, el ser (controlador) puede elegir desconectarse; mientras que el amo (poseedor) puede romper el bicho en mil pedazos o simplemente dejar que la batería del kentuki se descargue completamente. En cualquiera de esos casos, la conexión habrá finalizado para siempre. Ese kentuki no servirá nunca más y deberá comprarse otro para establecer una nueva conexión y ver si, esta vez, se tiene mejor suerte con el alma y/o escenario que ha tocado. Teniendo en cuenta que no son baratos, los kentukis no parecen ser precisamente descartables. Más bien, lo contrario. Es probable que se intente establecer una buena conexión duradera y única.

Al comienzo, novedosas y de nicho, estas mascotas digitales -que en ciertos momentos nos recuerdan al tamagotchi de los años 90 y en otros, nos hacen pensar en algunas de las redes sociales actuales- empezarán a conquistar el mercado masivo, formar parte de las noticias en los informativos centrales y volverse visibles en el espacio público a nivel global. Pero esa es toda la atención que se le prestará a caracterizar a este mundo cada vez más poblado de kentukis. Sin referencia alguna a cuestiones políticas, sociales o económicas, nada hace sospechar que el escenario sea futurista o distinto del que actualmente habitamos.

El foco de la atención está dirigido a las relaciones mediadas por kentukis (principal pero no únicamente afectivas), que en su expresión menos desarrollada se limitan a la mirada y a alguna comunicación rudimentaria. De este modo, las historias -algunas breves; otras extensas; algunas cuyo protagonista es amo; otras, ser- nos hablarán de esos vínculos, tematizando y problematizando variadas aristas de las relaciones mediadas por tecnologías digitales: el rol de la mirada, en esta sociedad en que hace tiempo, "años quizás", no se ve "a alguien con los ojos cerrados" (Schweblin, 2018: 167); los límites a la exposición de la intimidad, las relaciones de poder entre quien mira y quien es mirado, los riesgos y las virtudes de las relaciones anónimas, la soledad, el afecto, etc. Aunque la contratapa del libro señala al "voyeurismo" como línea principal de lectura, esta arista es, en nuestra opinión, una más entre otras posibles, y solamente describe el núcleo de algunas de las historias narradas. 
Todo ello está involucrado en la gama de personalidades más variada que podamos imaginar (personas maternales, solitarias, interesadas, personas buscando entretenimiento, amor, dinero, excitación sexual, curioseando y más).

Hasta aquí, un raconto sencillo pero necesario para que un lector curioso imagine lo que la novela habrá de ofrecer. Nada de lo dicho le impedirá disfrutar de la trama.

\section{Tecnologías digitales y sociedad en Kentukis: una mirada general}

A partir de ahora, nos embarcamos en nuestra segunda tarea: ¿qué nos dice Kentukis sobre el imaginario de las tecnologías digitales en la ficción?, ¿cómo y para qué nos vinculamos a ella?, ¿qué temáticas emergen que problematicen la presencia de estas tecnologías en las relaciones sociales?, ¿qué aspectos de los kentukis pueden servir para pensar a las tecnologías digitales que conocemos?

Comenzamos por aproximarnos a la visión general con la que es abordada la relación tecnología - sociedad en la novela. ¿En qué polo de esta relación está enfocado Kentukis? ¿Por dónde pasan sus preocupaciones? ¿Tienen política, tienen valores, los kentukis? ¿Nos imponen una forma de relacionarlos? ¿Es, en cambio, la sociedad la que le impone el desarrollo o los límites a sus potencias? Naturalmente, las respuestas a estos interrogantes no pueden nunca ser categóricas. Sin embargo, no pocos elementos de los que recorren el hilo del texto sugieren que esta ficción tiene el acento puesto en el segundo polo del binomio tecnología - sociedad, incluso acercando varias de sus preocupaciones a las propias de lo que se conoce como la teoría instrumental o el determinismo social de la tecnología (Feenberg, 1991; Winner; 1999). Entre los elementos que respaldan este señalamiento podemos mencionar los siguientes.

En primer lugar, no hay un modo de uso o finalidad prefigurados en el diseño de los kentukis. El manual de instrucciones deja atónito a más de un personaje en este sentido: se halla solamente alguna indicación precaria sobre el modo de carga del bicho y algún otro elemento relativo al hardware. En segundo lugar, como mencionamos, las funciones tecnológicas son bastante limitadas. En esta tecnología -reza uno de los personajes principales- no hay "nada nuevo"; no es otra cosa que "un cruce entre peluche articulado y un teléfono" (Schweblin, 2018: 26), "un teléfono con patas" (Schweblin, 2018: 107), y, sin embargo, toda una 
variedad de relaciones se construirá a partir de ella. En tercer lugar, no hay menciones ni interrogantes formulados por los personajes acerca de los fabricantes, alguna empresa, el software, el algoritmo que regula los matches, ni ningún elemento vinculado al diseño de esta tecnología, como sí los hay respecto de muchas otras cuestiones que rodean a los kentukis. Solo se menciona, al pasar, su origen chino. El diseño de la tecnología no es mayormente cuestionado. En Kentukis, la tecnología está allí, ha llegado a los hogares. A través de las historias se intentará responder a la pregunta acerca de cómo la sociedad se apropia de ella.

¿Para qué sirven o para qué fueron diseñados los kentukis entonces? En efecto, cada usuario habrá de resolverlo. Así, el cuarto y principal elemento que abona la presencia de una cierta visión instrumental de la tecnología es la trama del conjunto de historias. Estas revelan una multiplicidad de usos y diferentes grados de desarrollo de las potencialidades tecnológicas de los kentukis que dependen siempre de las motivaciones y valores de sus personajes, de sus acciones y omisiones, y de los límites o libertades que estos impongan a su relación.

Así, por ejemplo4, un kentuki en manos de tres adolescentes de una preparatoria de algún lugar de Estados Unidos sirve al chantaje de una compañera que, por algún motivo, es objeto de bullying. Este uso requerirá de alguna comunicación con el kentuki, que se resolverá colocando un tablero de "Ouija" para que el bicho conteste preguntas moviéndose sobre las letras y que les permitirá intercambiar correos electrónicos y fotos. Un kentuki adquirido por una madre preocupada por los posibles efectos de su reciente divorcio sobre su hijo pre-adolescente es utilizado para acompañar y vigilar el cotidiano de su niño en Umbertide, Italia. En la que es una de las historias principales de la novela, otro kentuki es utilizado como mascota por una joven mendocina que, en solitario y sin mucho con qué llenar sus días, acompaña a su pareja a una residencia artística en Oaxaca. Para ello se propondrá, aunque no necesariamente logrará, evitar traspasar los límites de una relación de mascota, limitando, en otras cosas, la comunicación con el kentuki. Algún kentuki en otras zonas del globo recibe dinero de un taxista, quien lo utiliza para conocer radares y evitar multas, y otro tanto ocurre con uno "entrenado" por un vagabundo para brindar pronósticos de futuro a transeúntes a cambio de unos pocos pesos.

\footnotetext{
${ }^{4}$ La siguiente información hace fundamentalmente a la presentación de algunas de las historias.
} 
Algo equivalente podemos observar desde la perspectiva de los "seres". En una historia breve, un controlador en manos de un personaje rodeado de muerte y miseria, se convierte en fuente de desconexión momentánea de la propia realidad, cuando sus ojos insertos en el kentuki pasean felices, alzados en hombros de otrxs, por algún evento en otra parte del mundo. En un sentido similar, un controlador en manos de un niño guatemalteco en duelo por la reciente muerte de su madre es utilizado para intentar conocer la nieve en el norte de Noruega y completar así aquella promesa que ella dejó inconclusa. Por su parte, desde Zagreb, un señor hace uso de múltiples controladores de modo simultáneo con el único fin de ganar dinero, vendiendo conexiones usadas. En cambio, en manos de un auténtico pedófilo, un controlador puede canalizar las más profundas miserias del ser humano en un kentuki. Según las noticias, hay cientos de casos denunciados.

En síntesis, el kentuki, un simple bichito, puede ser utilizado para los más diversos fines, dependiendo de las personalidades, digamos, los valores de los personajes que se relacionan a través de ellos. Poco hay de esencial en esta tecnología que imprima un uso determinado.

Naturalmente, las historias no son lineales y las intenciones originales de los personajes no siempre coinciden con los usos que terminan teniendo los kentukis. Aparecen, obviamente, los conflictos [Alerta spoiler]. Estos conflictos y los desenlaces que provocan le imprimen una mirada pesimista, e incluso fatalista, al uso de estas tecnologías que podría hacernos pensar en otro tipo de encuadre de la relación tecnología - sociedad. Podría sugerirnos la existencia de alguna esencia en el diseño de la tecnología que conlleva la fatalidad. Independientemente de lo que queramos hacer con ella, algo escapa a nuestro control, algo inherente a ella. Particularmente Kentukis le pone, como veremos luego con algo más de detalle, mucha atención al diseño azaroso y anónimo de las conexiones y, en efecto, algunas historias están muy atravesadas por esta cuestión. Sin embargo, en muchas otras el anonimato pasa a segundo plano (o está incluso ausente por distintos motivos) y son los celos, la desconfianza, el amor, la infidelidad y demás yerbas (muchas veces objetivadas en los kentukis) las que explican los conflictos. En esta línea, la narración es efectiva cuando nos va llevando, como lectores, a pasar por alto aquel momento en que, acompañando a los personajes, hemos habilitado o deshabilitado, por acción u omisión, ciertas potencialidades de las tecnologías. Más aún, en algunas 
oportunidades, será subrayado cuán fácilmente los personajes olvidan que podrían, mediante un simple click, desactivar todos los conflictos.

El pesimismo emergerá, entonces, cuando lleguemos a pensar que la oscuridad, las ambivalencias en los límites, aquellos elementos que han llevado al destino fatídico de las historias no están en otro lado más que adentro nuestro, incluso cuando tenemos "buenas intenciones".

Así, si tuviéramos que aventurar una lectura, diríamos que, aun en este giro pesimista, el foco primordial de la relación tecnología - sociedad sigue estando en lo que los sujetos hacen con las posibilidades que abren las TD y no tanto en lo que su diseño les impone.

Considerando que esta, la sociedad de kentukis, es una sociedad global; considerando, además, que los kentukis traspasan -algunas ${ }^{5}$ - clases sociales, de existir una esencia, esta está en el ser humano. No parece azaroso, ahora, que en uno de los epígrafes, antes de comenzar el viaje al mundo de los kentukis, la novela nos ofrezca la siguiente advertencia: "Antes de encender el dispositivo, verifique que todos los hombres estén resguardados de sus partes peligrosas. Manual de Seguridad. Retroexcavadora JCB, 2016”.

\section{Las relaciones mediadas por kentukis: algunos hilos temáticos}

Como mencionamos más arriba, son varias las aristas de las relaciones mediadas por tecnologías digitales tematizadas en el texto, y dan cuenta de las preocupaciones que en esta ficción rodean a las TD. En este sentido, llevan mucho más a formularse preguntas que a obtener respuestas. A continuación, señalaremos brevemente algunas de ellas.

\footnotetext{
${ }^{5}$ Los kentukis son caros y en efecto son adquiridos por las clases, digamos, incluidas. Sin embargo, tampoco son un privilegio de pocos. Además de la emergencia de un mercado paralelo de usados, que volverá algo más accesibles a las mascotas, la gente ahorra durante meses para comprarlos.
} 


\subsection{E1 afecto mediado por TD: soledad- atención, intimidad y ámbito privado}

Aunque, como hemos mostrado, existe una diversidad de historias, en varias de las que ocupan gran parte del libro, las relaciones que buscan establecerse vía kentukis son principalmente afectivas.

El contexto que parecería abrirles la puerta es el de una sociedad propia del capitalismo actual o, cuanto menos, de una sociedad en proceso de transformación. No hay familias tipo completas ni numerosas rodeando a los personajes, sino padres divorciados, hijos con alguna figura parental ausente $\mathrm{o}$, inversamente, madres sin sus hijos, tíos sin sus sobrinos, etc. En más de una oportunidad, esta ausencia es producto de una actividad laboral radicada lejos de la familia, en esta sociedad que parece tomar nota de la internacionalización de las relaciones laborales. Así, los personajes transcurren gran parte de su cotidianeidad en soledad -física-.

Sin embargo, y probablemente vinculado a este contexto de emergencia, las relaciones afectivas que buscan ser realizadas a través de los kentukis poseen solo algunas de las características que nos invitan a forjar hoy las más extendidas redes sociales o, más genéricamente, el capitalismo informacional como totalidad. En lo sustancial poseen, o intentar imitar, las características propias de las relaciones no mediadas y del capitalismo industrial.

En primer lugar, estas relaciones no tienen nada de "líquidas" ni de efímeras (Bauman, 2015). Las hay de amor romántico, de "cuidado maternal", de compañía, etc. y de una intensidad (medida en tiempo y atención) tal ${ }^{6}$ que, incluso, llega a crearse un cementerio para kentukis. Tampoco son relaciones múltiples, sino entre dos. De hecho, para sortear los problemas de lenguaje, el kentuki cuenta con un traductor automático que, una vez identificado, sólo se ocupa de traducir al amo, dejando incomprensibles las conversaciones que lo rodean. En este sentido, la llamada extimidad, la espectacularización del yo (Sibila, 2008) o la búsqueda de reconocimiento de uno a muchos que puedan otorgar los "me gustas" o "los seguidores" no tienen lugar en estas relaciones

\footnotetext{
${ }^{6}$ Quizás sea por esta misma razón que no se hace mención a la posibilidad de instalar el controlador del kentuki en el teléfono móvil, dispositivo a través del cual el vínculo podría ser de alta disponibilidad, pero no de atención focalizada.
} 
mediadas por tecnologías. Finalmente, son relaciones que intentan ser preservadas en el ámbito privado.

Con esta propuesta, la novela problematiza, aunque no necesariamente clausura, dos cuestiones que suelen ser objeto de discusión respecto de las relaciones mediadas por TD extendidas en la actualidad.

Por un lado, el lugar que ocupan estas relaciones en la construcción de significado e identidad en las sociedades actuales, en comparación con las no mediadas, locales, primarias, etc. Mientras que, por ejemplo, para autores como Castells (1997), la identidad se estructura hoy en una suerte de esquizofrenia estructural entre lo local y lo global, el yo y la red; la novela parece sugerir que lo que existe en la sociedad de los kentukis es un reemplazo de lo local, de las identidades primarias, a manos de la red. En efecto, el increscendo en la comunicación y la intensidad de las relaciones vía kentukis correrá en paralelo a la disminución de la atención a los -pocos- vínculos primarios de los personajes. Las relaciones mediadas por TD consumen un tiempo y atención que son finitos. De este modo, no complementan, sino que compiten con las relaciones "del mundo real", contribuyendo a desplazar las relaciones afectivas del mundo no digital. Se plantea, así, la paradoja de que la tecnología podría reforzar aquellas mismas problemáticas que, en Kentukis, nos mueven a utilizarla: esta sociedad, en la que la soledad es una constante, busca los vínculos primarios perdidos en el mundo no digital a través de las TD y, junto con ello, termina por dilapidar los pocos que aún lo habitan.

Vinculado a ello, el otro aspecto que problematiza, sino denuncia, es el carácter de "artificialidad" del afecto cuando se encuentra mediado por TD. Los personajes se preguntan, una y otra vez, por qué sufren, por qué aman, por qué se preocupan por aquello que "en verdad no existe". Esta cuestión no sólo emerge en palabras de los personajes. Una tonalidad gris y textura metálica recorre el escrito. Los kentukis son peluches, cuestión que los asociaría a la ternura, a la afectividad, pero constantemente emiten ruidos metálicos. Sus colores, por lo demás, son exageradamente estridentes (fucsias con pintitas blancas, turquesas con lunares violetas vivos, etc.). Estos elementos sugieren la presencia de un afecto artificial.

Así, en la sociedad de los kentukis se lamenta, al menos en parte, la pérdida de aquellos lazos sociales no mediados y particularmente de los vínculos primarios intensos, tan característicos del capitalismo industrial. 


\subsection{El rol de la mirada en las relaciones mediadas por TD}

Ahora bien, como mencionamos, otras aristas de estas relaciones tienen características que se encuentran muy presentes en las relaciones mediadas por TD típicas de algunas redes sociales que hoy frecuentamos. Sobre ellas la novela propondrá algunas preguntas. Una de estas características es la preponderancia de la mirada y su rol en estas relaciones.

En primer lugar, en lo que podría ser una referencia a Erich Fromm, la narración parece trazar, o mejor dicho, someter a discusión, una distinción en los roles del amo y el ser. Se trata en definitiva del intento de separación analítica de aquello que en las redes sociales hace un mismo usuario en diferentes momentos, cuando "publica" y cuando "mira". El amo "mendiga la mirada", quiere "tener" la mirada de un otrx a disposición, busca su reconocimiento. El "ser" mira, participa con la mirada de la vida del otro, vive la vida del otro a través de la mirada, y esa es "la condición más intensa" en esta relación. La novela invita al lector, a preguntarse, así, qué busca, qué lo motiva, cuando está de uno y otro lado. Si tomamos en cuenta el contexto solitario descrito más arriba y la posible referencia al autor mencionado, Kentukis podría estar sugiriendo -y esto es solamente una hipótesis o posible lectura- una crítica a la sociedad actual en la que los sujetos, representados esta vez en los amos, buscan suplir las falencias del "ser" con el “tener" (Fromm, 1977; 2007).

En segundo lugar, emerge la pregunta por el deber ser de la mirada. ¿Qué aspectos de la vida no deberían ser mirados o expuestos a la mirada? ¿Es inofensiva la mirada? Desde la perspectiva de los poseedores de kentukis, naturalmente, emergerá la problemática vinculada a los usos no deseados de la información que la mirada provea. Pero desde la perspectiva de los controladores de kentukis también se mostrará lo dañina que puede ser una imagen en sí misma, por ejemplo, para un niño.

Finalmente, se destaca una breve historia que logra poner con crudeza sobre la mesa cómo, en esta sociedad de ojos abiertos, no solo no todo es objeto de 
mirada, sino que algunas cosas, incluso, no quieren ser miradas [Alerta spoiler en la nota al pie $]^{7}$.

\subsection{Conocimiento, comunicación y poder: el anonimato en las relaciones mediadas por TD}

Una de las aristas más relevantes que recorre a las historias es la temática del poder vinculado al conocimiento, tópico muy abordado y actual en las ciencias sociales (véase, por ejemplo, Foucault, 1992, 2006; Castells, 2009). En general, en varias historias se revela el poder que tiene un sujeto sobre otro a partir de las asimetrías del acceso a la información de diverso tipo, sobre todo, cuando recurriendo a otras tecnologías- puede registrarla y utilizarla para diversos fines. También se le da lugar al problema inverso: cuando un sujeto, aun con buenas intenciones, juzga y toma decisiones sobre otrx en base a información que se presenta como incompleta. Teniendo en cuenta lo que sugerimos en la primera sección, todo ello parece exceder por momentos a las particularidades que asume la información cuando se digitaliza y registra, poniendo el foco, más genéricamente, en el poder del conocimiento y, sobre todo, en lo que los sujetos hacen con el conocimiento que tienen a disposición. En este sentido, la novela se limita al plano de los sujetos particulares, sin preocuparse por instituciones, corporaciones o gobiernos.

La mayor preocupación, sin embargo, gira en torno a una forma de conocimiento particular y vinculado directamente a las tecnologías digitales: el de la identidad de lxs conectadxs. Como hemos mostrado, este conocimiento es asimétrico. El controlador del dispositivo que, a este respecto, podemos asociar a cualquier navegante de la web en sus orígenes, -digamos sintéticamente- puede mentir o directamente no comunicarse. Nada habrá que el amx pueda hacer para acceder a información sobre su identidad. El amx, por su parte, aunque puede administrar cierta información y limitar el acceso al conocimiento del kentuki, brindará al menos una serie de datos autenticantes con el solo hecho de exponerse a la mirada. La novela ofrece, así, con detalle la descripción del proceso de autenticación en la web y las diferencias que lo separan de aquel que ocurre en las relaciones no mediadas (Lessig, 2009), jugando con la pregunta de quién es el verdadero amx en esta relación.

\footnotetext{
${ }^{7}$ Menos de un cuarto de hora se mantienen encendidos, antes de arrojarse a un precipicio, dos kentukis que fueron adquiridos en un hogar de ancianos para entretener a sus hospedados. No sabemos quién está detrás de los controladores y eso es lo interesante: sea quien sea, nadie quiere mirar a la vejez.
} 
Ahora bien, a través de algún personaje se partirá de la premisa de que ser anónimo en las redes es "una condición a la que ya es casi imposible aspirar" (pp. 108). La pregunta que nos hace Kentukis, entonces, es: ¿Es esto algo deseado o indeseado? La respuesta no es concluyente. Se trata, en cambio, de mostrar las bondades y los riesgos que el anonimato trae aparejado.

Por un lado, el anonimato aparece como aquello que nos otorga "la máxima libertad posible como usuarios” (pp. 108). Nos permite ser auténticos. Más aún, un Club de Liberación de kentukis será fundado para que ya nadie pueda ser sometido a los caprichos de lxs amxs. Parecería, en ese sentido, que hemos perdido un valor deseado, estando hoy sometidos a un control de potencia global (Boyle, 1997; Deleuze, 2006). Sin embargo, la otra cara de la moneda está, primero, en la necesidad de responsabilización de los actos de estos "nuevos ciudadanos anónimos" ante hechos que juzgamos incorrectos. Segundo, en la posibilidad de generar daño a otrxs justamente por desconocer su identidad.

En este sentido, lo que en la novela aparece como la "comunicación" entre seres y amxs (y que más genéricamente podría pensarse como el acceso democrático a la información) se muestra como una herramienta fundamental para transformar las relaciones sociales. El conocimiento y la información pueden transformar a un conejito tierno en un "viejo verde" y pueden, más ampliamente, transformar relaciones asimétricas en relaciones entre pares.

\subsection{El negocio de los kentukis y la regulación capitalista}

Una última temática que emerge en repetidas ocasiones es la de las regulaciones que rodean a las TD. Por un lado, aparece ligada, como mencionamos hace un momento, a la responsabilización por los actos de los kentukis: ¿deberían tener derechos y obligaciones los kentukis? Sin embargo, cuando más se hace mención a las regulaciones es al abordar la historia de aquel sujeto que vende conexiones usadas. Aquí la novela toma nota de la importancia de las regulaciones internacionales. Toma nota también de que, aunque tardías, las primeras regulaciones que llegan son las que se vinculan con el carácter mercantil de las tecnologías.

En efecto, un buen hombre croata, apremiado por su situación económica, hijo de padre jubilado a quien tiene a cargo, decide incursionar en un negocio de conexiones: compra tablets y conexiones, las transita durante un tiempo, apunta 
algunas características de lxs amxs y escenarios en que pasean sus kentukis y las comercializa usadas a quien quiera evitar tantas sorpresas. En ese contexto, el croata festeja y se sorprende a la vez de que aún no haya entrado en vigencia alguna normativa internacional que prohíba su negocio.

Sin embargo, el verdadero negocio no está tematizado: ¿Quién crea y vende a los kentukis? ¿Su negocio se agota en la venta del artefacto? ¿Qué pasa con todos los datos e imágenes producidos por los usuarios, amxs y seres? ¿Qué regulaciones recaen sobre los mismos? (Boutang, 1999; Zukerfeld, 2008, 2010). ¿Quién tiene acceso a las interacciones entre amos y kentukis? ¿Y qué lugar ocupan estas en el negocio de los kentukis? (Petersen, 2008; Andrejevic, 2009; Fuchs, 2010; Briziarelli, 2014) ¿Qué poder económico y social puede tener sobre los sujetos una empresa como la que comercializa los kentukis? (Resichl, 2008)

Los negocios, tanto el del croata como los de aquellos que mencionamos en segundo plano (el del taxista o el vagabundo), remiten a pequeños espacios mercantiles que nos recuerdan mucho más al menudeo de la piratería por usuarios ignotos o al de un pequeño comerciante que vende sus productos vía Facebook que a Mark Zuckerberg. El principal negocio, el de los kentukis, y las regulaciones que le competen, no es tematizado.

Llegamos al final de esta reseña. Naturalmente, las líneas mencionadas son solo algunas de las que atraviesan a Kentukis. Otras tantas nos habrán quedado en el tintero. Aun así, hay al menos tres cuestiones centrales que podemos concluir.

La primera es que, en este imaginario, las tecnologías digitales tienen un fuerte rol afectivo en las sociedades actuales. En ese sentido, abren una diversidad de posibilidades que conllevan inevitablemente al cuestionamiento de las relaciones que en el capitalismo industrial se encontraban estabilizadas y naturalizadas (los vínculos primarios, las relaciones duraderas, fundadas en la intimidad, etc.). En segundo lugar, la sociedad de kentukis se encuentra, respecto de las TD, en ese exacto momento, en el del cuestionamiento, el de las preguntas. Entre lo que muere y lo que nace, no se ofrecen elementos firmes para denostar o enarbolar los valores de una y otra era. Lo que está claro es que se encuentran en proceso de transformación.

Finalmente, aun siendo las tecnologías digitales parte nodal de la trama de Kentukis, las preocupaciones están fundamentalmente orientadas a problematizar la forma en que nos relacionamos con ella, dejando poco espacio a las preguntas 
por el cómo y el quién de su construcción, diseño y posible transformación. Ahora podemos reformular, para concluir, algo que intencionalmente mencionamos de otro modo al comienzo: los protagonistas de la novela no son los kentukis, sino los seres humanos. Recurriendo a la imagen de tapa, Kentukis parece decirnos: si nos sacamos la careta de kentuki, detrás, estamos nosotrxs.

\section{Referencias}

Andrejevic, M. (2009). Exploiting YouTube: Contradictions of user-generated labor. En The YouTube Reader. Stockholm: National Library of Sweden.

Bauman, Z. (2015). Modernidad líquida. México D.F.: Fondo de cultura económica.

Boyle, J. (1997). Foucault in cyberspace: Surveillance, sovereignty, and hardwired censors. U. Cin. L. Rev., 66, 177.

Boutang, Y. M. (2004) Riqueza, propiedad, libertad y renta en el capitalismo cognitivo. En VV.AA. Capitalismo cognitivo, propiedad intelectual, y creación colectiva (pp.107-120). Madrid: Traficantes de sueños.

Briziarelli, M. (2014) The Dialectics of Voluntariat 2.0: Producing Neoliberal Subjectivity through Facebook. Special Issue "Free And Unpaid Work: Gratuity, Collaborative Activity And Precariousness". Sociologia del Laboro n¹33, pp.133-144. DOI: 10.3280/SL2014-133009

Castells, M. (1997). La era de la información: economía, sociedad y cultura. Vol I: La sociedad red. Madrid: Alianza editorial.

(2009) Comunicación y poder. Madrid: Alianza Editorial.

Deleuze, G. (2006). Post-scriptum sobre las sociedades de control. Polis. Revista Latinoamericana, (13).

Feenberg, A. (1991). Critical Theory of Tecbnology. New York: Oxford University Press.

Fuchs, C. (2010) Labour in Informational Capitalism. En The Information Society European Journal of Social Theory 26(3), 179-196. DOI: $10.1080 / 01972241003712215$ 
Foucault, M. (1992) Las redes del poder. Buenos Aires: Almagesto. (2006) Seguridad, territorio, población. Buenos Aires: Fondo de Cultura Económica.

Fromm, E. (1977). El miedo a la libertad. Buenos Aires: Paidós . (2007) El arte de amar. Buenos Aires: Planeta.

Lessig, L. (2009) El código 2.0. Madrid: Traficantes de sueños.

Petersen, S. (2008) Loser Generated Content: From Participation to Exploitation. First Monday, 13 (3).

Reischl, G. (2008). El engaño Google: una potencia mundial incontrolada en Internet. Barcelona: Medialive Content.

Sibilia, P. (2008). La intimidad como espectáculo. Buenos Aires: Fondo de Cultura Económica.

Winner, L. (1999) ¿Tienen política los artefactos? (Do Artifacts have Politics?). En MacKenzie, Donald, y Wajcman, Judy (eds.). The Social Shaping of Technology. Philadelphia: Open University Press.

Zukerfeld, M. (2008). El rol de la propiedad intelectual en la transición hacia el capitalismo cognitivo. Argumentos. Revista de crítica social, (9).

(2010). Capitalismo y conocimiento. Materialismo cognitivo, propiedad intelectual $y$ capitalismo informacional (Tesis de Doctorado, FLACSO Argentina).

Disponible

en https://capitalismoyconocimiento.wordpress.com. 